\title{
Contribuições de Vigotski para a compreensão do psiquismo'
}

\author{
Vygotsky's contributions for \\ understanding the psyche
}

\author{
Vera Lucia Trevisan de SOUZA² \\ Paula Costa de ANDRADA ${ }^{2}$
}

\begin{abstract}
Resumo
Este artigo é resultado de muitas leituras, estudos, reflexões e debates de um grupo de pesquisa que toma a Psicologia Histórico-Cultural como aporte teórico e metodológico. Sua natureza é teórica, visto que decorre dos escritos de alguns de seus estudiosos para apresentar compreensões das ideias centrais de Vigotski, principal teórico da referida abordagem. Objetivamos reunir e discutir conceitos-chave desse autor, os quais se encontram dispersos em sua obra, com o intuito de apresentar suas possibilidades de interpretação e aplicação em estudo e práticas sobre o desenvolvimento humano. A complexidade da obra do autor demanda inúmeras investigações devido ao caráter dialético e complexo de suas postulações. Buscamos, assim, demonstrar neste texto a plausibilidade de sua teoria para explicar os fenômenos psicológicos, oferecendo contribuições e sugerindo ações que possam respaldar a prática do psicólogo em contextos institucionais, principalmente a escola.
\end{abstract}

Unitermos: Materialismo dialético; Psicologia Histórico-Cultural; Psiquismo; Vygotsky (Lev).

\begin{abstract}
This article is the result of many readings, studies, reflections and debates of a research group that takes Historical-Cultural Psychology as its theoretical and methodological basis. Its nature is theoretical, in that it results from the writings of the authors of this approach and some of his researchers to present understandings of the major concepts of Vygotski, its most important theoretician. It aims to gather and discuss the key concepts of this author, which are scattered throughout his work, in addition to introducing their interpretation and application possibilities in the study and practice on human development. The complexity of the work of the author demands countless studies and the commitment to the dialectical and complex aspect of his theories. We therefore seek to demonstrate in this text the plausibility of his theory to explain psychological phenomena, providing contributions and suggestions for actions that can support the practice of psychologists in institutional settings, especially schools.
\end{abstract}

Uniterms: Dialectical materialism; Historic cultural psychology; Psyche; Vygotsky (Lev).

\footnotetext{
$\boldsymbol{\nabla} \mathbf{v} \boldsymbol{v}$

1 Levando-se em consideração as diferentes formas de escrita do nome do estudioso russo Lev Semenovich Vygotsky (1896-1934) - Vygotsky, Vigotsky, Vygotski, Vigotskii, Vigotski, entre outras -, a forma usual neste trabalho será Vigotski, exceto as referências, as quais serão escritas conforme a grafia do texto original.

2 Pontifícia Universidade Católica de Campinas, Centro de Ciências da Vida, Pós-Graduação em Psicologia. Av. Jonh Boyd Dunlop, s/n., Prédio Administrativo, Jd. Ipaussurama, 13059-900, Campinas, SP, Brasil. Correspondência para/Correspondence to: V.L.T. SOUZA. E-mail: <vtrevisan@puc-campinas.edu.br>.

Apoio: Conselho Nacional de Desenvolvimento Científico e Tecnológico.
} 
Este artigo, de natureza teórica, apresenta a compreensão das autoras sobre alguns conceitos fundantes da obra de Lev Semmenovit Vigotski, os quais têm iluminado a reflexão do grupo de pesquisa a que se vinculam seus estudos. São três os objetivos deste texto. O primeiro, de natureza teórica, é reunir e discutir conceitos-chave desse autor para o estudo do desenvolvimento humano, os quais se encontram dispersos em sua obra. O segundo, de cunho mais metodológico, apresenta as principais premissas do método dialético, proposto pelo autor como o mais adequado para investigar os fenômenos psíquicos da perspectiva da Psicologia Histórico-Cultural. O terceiro, de natureza interventiva, visa refletir sobre as contribuições dos conceitos de Vigotski para a prática do psicólogo em contextos institucionais, sobretudo a escola.

Pretende-se, ainda, de modo subjacente aos objetivos anunciados, que ao reunir os conceitos de Vigotski em um mesmo texto, organizados segundo uma compreensão fruto de muito estudo e reflexão, possa oferecer uma visão no mínimo diferente daquelas expostas em outras produções. Contudo, tal intento não se relaciona à ideia de que essa concepção que ora se apresenta seja melhor ou pior que tantas outras já publicadas, mas, seguindo a perspectiva do próprio autor no que concerne ao processo de atribuição de sentidos e significados aos elementos da cultura, quer-se com este texto apresentar novas possibilidades de interpretação e aplicação dos postulados do autor, sobretudo no que diz respeito à dimensão que a afetividade assume em sua obra (Toassa, 2009).

Vigotski (1927/1995; 1927/2004) enfatiza que qualquer aspecto investigado deve ser estudado historicamente em todas as suas fases de desenvolvimento, desde o momento de seu aparecimento até a sua dissipação. Deste modo, para falar dos conceitos deste autor é necessário retomar as origens da Psicologia Histórico-Cultural, em cuja história se assentam suas bases teórico-metodológicas. Esse pressuposto demanda que se inicie o presente artigo abordando o nascimento das ideias que abalizaram a Psicologia Histórico-Cultural e o contexto histórico em que estas se desenvolveram.

O período pós-revolução russa nos anos 1920 e 1930 do século XX é o marco desta história. É nessa 356 época que Vigotski, Luria e Leontiev dão início a uma série de trabalhos conjuntos com um grupo de jovens intelectuais da Rússia, que buscava uma ligação entre o novo regime e a crescente demanda de produção científica. Entendia aquele grupo de jovens cientistas que uma psicologia comprometida com os ideais revolucionários deveria buscar suprir problemas sociais e econômicos da então União Soviética (Palangana, 1998). Segundo Tunes e Prestes (2009), a Rússia do início dos anos 1930 vivia um período marcadamente ideológico, onde a ciência, a cultura e a educação eram moldadas de acordo com as ideias do regime. Todas as produções científicas da época estavam sujeitas à crítica e a repressões do Comitê Central do Partido Comunista da Rússia.

Em meio a esse ambiente de crises e revoluções, Vigotski (1927/2004), também via que a Psicologia do mesmo período, final do século XIX e início do século $X X$, passava por uma crise. Ele fez tal afirmação partindo do princípio de que havia uma dicotomia dentro da Psicologia, caracterizada por duas correntes opostas: o idealismo e o mecanicismo. Sua análise o levou à constatação da existência de uma crise metodológica, já que a forma de se acessar o humano por caminhos opostos parecia estar equivocada. Sua proposta era que se estudasse o ser humano em sua totalidade, tomando-se como central a relação social dialética e de interdependência em sua constituição. Sua reflexão sobre o que seria uma nova ciência psicológica gera as bases para a estruturação do método da Psicologia Histórico-Cultural: o materialismo dialético.

Pautado em princípios do marxismo e influenciado por outras obras da filosofia, em especial a de Espinosa, Vigotski dá início à postulação de uma Psicologia cujos preceitos se assentam no que alguns autores denominam de ética humanista (Delari Jr, 2009; Puzirei, 1989). Segundo Delari Jr. (2009), tal ética não se filia à ideia de homem essencialmente bom - humanismo ingênuo, nem tampouco aos ideais liberais de realização individual, mas se vincularia ao modo de agir humano que, no caso da abordagem da Psicologia Histórico-Cultural, envolveria três ações: a superação, a cooperação e a emancipação. A primeira, diz respeito à necessidade de superarmos os limites atuais de nossas ações, de nosso modo de viver e ser, em direção ao que podemos ser ou alcançar. Nesse sentido, para Vigotski, a realização humana só é possível pela supe- 
ração. Entretanto, pela ênfase dada ao papel da cultura na constituição do humano, essa superação exige condições materiais e concretas para sua realização e, a principal condição, seria a cooperação entre as pessoas.

Assim, a superação viabilizada pela cooperação é que levaria o homem à emancipação como conquista da liberdade de pensamento e ação, exercida no coletivo, com o coletivo e pelo coletivo. Considerar esses princípios é fundamental para a compreensão da teoria do desenvolvimento humano elaborada por Vigotski. O processo de se humanizar, a partir de um arcabouço biológico herdado pelo sujeito, tem como central o social e, no modo de compreender do autor, mais se assemelha a uma revolução do que a uma evolução. Isso porque envolve a ação permanente do sujeito em relação ao meio, o qual é considerado fonte de desenvolvimento, visto que dele derivam o conteúdo e a dinâmica que, apropriados pelo sujeito de modo próprio e singular, constituirão seu sistema psicológico e sua personalidade. Nas palavras de Vigotski (1935/2010):

As funções psicológicas superiores da criança, as propriedades superiores específicas ao homem, surgem a princípio como formas de comportamento coletivo da criança, como formas de cooperação com outras pessoas, e apenas posteriormente elas se tornam funções interiores individuais da própria criança (p.699).

É sobre o processo de desenvolvimento que se centra na constituição do sistema psicológico, o papel do meio, as funções psicológicas em si e suas relações, e sobre a ideia de sentido e de vivência que discorremos a seguir.

\section{A concepção de funções psicológicas superiores como um sistema de nexos}

Como Vygotski (1934/2001) se inspira no materialismo dialético de origem marxista para postular os fundamentos da evolução do psiquismo, ele aborda o desenvolvimento humano a partir da fase mais elementar da estrutura psíquica, desde os processos inferiores involuntários, da ordem do biológico. Quando em contato com os elementos da cultura, essas estruturas psíquicas primitivas evoluem mediadas pela atividade prática do homem: o uso de instrumentos, a divisão social do trabalho, a própria necessidade de interação social.

O resultado do desenvolvimento histórico-social do homem leva à sua consequente evolução psíquica, culminando no que Vigotski denomina Funções Psicológicas Superiores (Vigotski 1925/2004b; 1933-1934/ 2006a; Vigotsky 1931/2007; Vygotski 1934/2001; Vygotsky 1934/2003). O aparecimento das Funções Psicológicas Superiores (FPS) está subordinado às incitações do ambiente que permeiam as experiências do sujeito desde seu nascimento. Assim, as funções psicológicas passam de natural a cultural quando mediadas. O sujeito, pela mediação do outro, converte as relações sociais em funções psicológicas, que passam a funcionar como sendo próprias de sua personalidade (Vigotski, 1927/1995).

O processo evolutivo do elementar ao superior não é paralelo ou sobreposto, mas resultado de combinações e nexos entre as funções, formando uma imbricada rede de sínteses entre elas: "Se estructuran a medida que se forman nuevas y complejas combinaciones de las funciones elementares mediante la aparición de síntesis complejas" (Vigotski, 1933-1934/2006a, p.118).

As Funções Psicológicas Superiores (FPS), como memória, consciência, percepção, atenção, fala, pensamento, vontade, formação de conceitos e emoção, se intercambiam nesta rede de nexos ou relações e formam, assim, um sistema psicológico, em que as funções se relacionam entre si. Esse processo não se esgota, pois, apesar da estrutura das FPS não mudarem, as conexões (ou nexos) mudam. Entende-se que os nexos são a própria configuração de novos significados e sentidos e isto se dá quando as FPS se cruzam no processo evolutivo, promovendo um salto no desenvolvimento do sujeito. O signo faz a conexão das FPS, pois é por meio dele que as funções se aglutinam no sujeito. Isto porque, é pelos signos que se efetivam as conexões/relações entre as diferentes FPS, pois somente deste modo as informações transitam e podem ser acessadas, uma vez que o signo "é o próprio meio da união das funções em nós mesmos, e poderemos demonstrar que sem esse signo o cérebro e suas conexões iniciais não podem se transformar nas complexas relações, o que ocorre graças à linguagem" (Vigotski, 1925/2004b, p.114). Apesar de ser necessária a mediação dos signos para 
haver conexões entre as diferentes FPS, essa mediação precisa ter um significado para o sujeito, ou seja, precisa fazer sentido para provocar relações e nexos entre as funções. Desta perspectiva, quem faz a mediação é o próprio sujeito e não o outro, ainda que ela seja possível pela via do outro.

Por meio do estudo do desenvolvimento das FPS abordar-se, neste artigo, algumas dessas funções e seus nexos dentro do sistema psicológico, o que é de grande relevância para a compreensão de outros conceitos da Psicologia Histórico-Cultural.

\section{Os conceitos de pensamento e fala}

"O pensamento é uma nuvem, da qual a fala se desprende em gotas"(Vigotski, 1925/2004a; p.182). Por meio desta afirmação poética Vigotski traz à tona a relação que pretendemos abordar neste item: a fala como expressão do psiquismo.

O autor salienta que não há como estudar o pensamento e a fala a não ser pelo método dialético, que confere um caráter histórico às questões ligadas ao comportamento humano. Ele afirma que a questão do pensamento e fala supera os limites das ciências naturais e se transforma em um fato histórico-social (Vygotski, 1934/2001). Segundo ele, é pela aquisição da fala que nos relacionamos socialmente e, ao mesmo tempo, interferimos na construção do meio. O que o sujeito pensa, interpreta e expressa é o que ele apreende de seu entorno, mas também, dialeticamente, é pela fala que este mesmo sujeito pode interagir e transformar o mundo (Vigotsky, 1931/2007).

Considera, o autor, que a fala, inicialmente, exerce a função de comunicação entre a criança e o meio e, nesse processo, vai construindo as condições para que se transforme em fala interna, quando exercerá a função de organizar o pensamento. A fala interna se desenvolve mediante as trocas estruturais e funcionais derivadas da fala social (Vygotski 1934/2001; Vygotsky 1934/2003). Por volta dos dois anos de idade, as curvas do desenvolvimento da fala e do pensamento se encontram, em um processo exclusivamente humano. $\mathrm{O}$ autor aponta que neste momento em que ocorre o estabelecimento de um nexo entre estas duas funções há um grande salto no desenvolvimento do sujeito. A partir deste salto advindo do desenvolvimento da fala, a criança pode explorar a relação entre signo e signi- ficado. A palavra, que era inicialmente para a criança uma propriedade externa do objeto, passa a ter um significado simbólico, que o autor denomina de função simbólica da fala. Essa conquista abre portas para a criança se apropriar de uma gama maior de experiências circundantes em sua realidade.

A palavra é o signo que conceitua e, ao mesmo tempo, representa o objeto, dando-Ihe sentido como um predicado do pensamento. À medida que a fala fica mais complexa, o pensamento também se torna mais desenvolvido. Cada estágio do desenvolvimento do significado das palavras representa também um novo estágio de desenvolvimento na relação entre pensamento e fala (Vygotsky, 1934/2003).

Por estes processos descritos por Vigotski é que o sujeito, cada vez mais, pode ampliar suas trocas com o mundo e, assim, expandir as representações do meio ao seu redor, formar novos conceitos, e desenvolver a consciência de si e da realidade. Daí a compreensão de que o sujeito é produto e produtor de sua história, constituição possível, justamente, por seu caráter histórico-social.

\section{A categoria de sentido}

Vygotsky (1934/2003) destaca que o sentido de uma palavra predomina sobre seu significado; uma mesma palavra possui um significado público que é compartilhado, porém, o seu sentido é algo construído em torno de uma complexidade de aspectos psicológicos privados que essa palavra faz emergir na consciência de cada um. Os sentidos são construídos por meio de lembranças, vivências, percepções únicas, singulares e que dependem do contexto em que são despertos.

Barros, Paula, Jesus, Colaço e Ximenes (2009) destacam que, para Vigotski, "o sentido é concebido como acontecimento semântico particular"(p. 179) fundamentado nos processos de singularização, mas que emergem das interações históricas e culturalmente construídas. Se o contexto muda, o sentido também muda, transformando-o em algo complexo e ilimitado, dependente da singularidade de quem o interpreta, constituindo uma realidade que não é pré-determinada, já que está em permanente modificação. 
Como os sentidos variam de acordo com uma gama de fatores psicológicos e contextuais, Vygotski (1934/2001) diz que eles são uma parte complexa e fluida da palavra; a soma de vários acontecimentos psicológicos que essa palavra desperta na nossa consciência. A expressão do discurso interior opera com o sentido do que é percebido e construído pelo sujeito.

O que significa dizer que os sentidos atribuídos a algo são a própria revelação dos afetos do sujeito, pois, para a compreensão do pensamento do outro não basta o entendimento de sua fala e de seu significado no dicionário. É preciso compreender suas motivações.

Todo este processo descrito até este momento é básico para o entendimento de outro conceito. $\mathrm{O}$ estudo do sentido, da fala, e do pensamento necessita estar relacionado com a consciência - concebida por Vigotski como a função das funções.

\section{A consciência humana}

Leontiev (1978) assinala que o desenvolvimento da consciência humana é estabelecido por motivações biológicas, mas também por fatores históricos e sociais. A atividade consciente do homem é algo que foi e vem sendo conquistado e transformado nas interações entre o sujeito e a atmosfera histórico-social. Para este autor, é por meio da atividade, da utilização dos instrumentos de trabalho e da comunicação e interrelação exigida nesse contexto de produção que o sujeito se desenvolve.

Pode-se entender consciência como a atribuição de sentido que ocorre quando o sujeito se apropria do processo de trabalho e da atividade envolvidas em relação a algo. Ao reconhecer sua ação, seu objetivo, seu percurso e o resultado deste processo, o humano adquire um saber de si, do outro ao seu redor em relação ao objeto que desencadeia esta ação. Deste modo, ter consciência é saber-se de si, do outro e da realidade e, para Vygotsky (1934/2003), conhecer algo é perceber seus significados e sentidos e dar-lhe novos contornos. Isto implica a capacidade de fazer conexões sobre a relação de um objeto com algum outro aspecto. A consciência de nossas ações faz com que sejamos aptos a dominá-las, interferindo e transformando-as e assim podendo agir e recriar a realidade. Dessa perspectiva, a consciência é a maior e mais importante função psíquica, e, para nós, corresponde ao próprio sistema psicológico como um todo.

A consciência leva à transformação e ao desenvolvimento e é por meio dela que o homem evolui, tornando-se capaz de estabelecer novos nexos e emancipar-se como sujeito ativo, que cria e recria sua realidade. Neste sentido, ela é o próprio devir humano.

Aqui se considera que a fala apresenta-se como pedra fundamental para o desenvolvimento da consciência, pois ela permite que o sujeito se comunique, faça a mediação da cultura e, além de favorecer a apropriação do externo promove a apropriação de si mesmo e, este saber-se de si passa a ser um fato da consciência (Vigotski, 1933/2004). A palavra, matéria prima da fala, captura as singularidades contidas no objeto e seus significados, pela generalização. Ao generalizar, expandimos o processo de significação da consciência; a palavra é uma forma de generalização que tem o poder de aglutinar conceitos, imagens, sentimentos, pensamentos e representações culturais, além de produzir nexos entre outras FPS.

Nesse rumo, Vigotski (1933/2004) aponta a importância da analise semiótica dos sentidos do sujeito como caminho para desenvolver a consciência. Afirma que "a verdadeira compreensão consiste em penetrar os motivos do interlocutor"(Vigotski, 1933/2004; p.184) e a fala é uma forma de se acessar os aspectos afetivo-volitivos vivenciados pelo humano, ou seja, os sentidos e significados de algo. Só atingimos a compreensão do eu e do outro por meio do acesso à motivação contida nos sentidos do que é pensado e falado e, Vigotski (1933/2004), chega a afirmar que esta é a única metodologia capaz de tal desafio.

Outra forma de acessar os sentidos e significados dos sujeitos como via de promoção de sua tomada de consciência e transformação é pela arte. Vygotsky (1925/2001) apresenta em sua tese de doutorado a possibilidade de se acessar os afetos, por meio das variadas manifestações artísticas.

\section{Afetividade}

Vigotski não desenvolveu uma Teoria da Afetividade, mas este aspecto constitutivo do sujeito e fundamental em seu desenvolvimento encontra-se mencionado em grande parte de sua obra, assim como sua 
relevância. Torna-se necessário dizer que, até há pouco tempo a questão da afetividade em Vigotski permaneceu inexplorada por seus estudiosos, fato que, de nosso ponto de vista, deve-se à grande complexidade dos conceitos que apresenta e à plausibilidade de muitos deles para a compreensão de dimensões do desenvolvimento às quais dedicou estudos mais aprofundados, desenvolvendo-os com maior clareza e precisão. A apreensão da afetividade na obra do autor exige um estudo vasto e profundo, uma vez que se apresenta de modo difuso em muitos de seus textos, atrelada a outros conceitos. Esse fator é um dos que pode ter contribuído para o não investimento de seus estudiosos em sua abordagem. Segundo Sawaia (2000), na obra de Vigotski as emoções "[...] compõem o subtexto de suas reflexões mais importantes, como: significado, educação, linguagem, pedologia e defectologia" (p.4). A autora credita à Vigotski o mérito de conferir à afetividade uma forma de positividade epistemológica, variável impor-tante para a investigação do humano e produção de conhecimento.

González-Rey (2009a, 2009b), estudioso do conceito de subjetividade dentro da Psicologia Histórico-Cultural, aponta que o aspecto afetivo-volitivo na teoria vigotiskiana está na base do desenvolvimento do psiquismo humano e, assim sendo, a subjetividade tem uma grande relevância na constituição do sujeito. Para o autor, Vigotski mostra em sua obra que a subjetividade é um processo que respalda as formas de organização que caracterizam os processos de significação e sentido do sujeito e do contexto social em que ele se desenvolve.

Vygotsky (1934/2003), em seu livro "Pensamento e Linguagem", defende que a afetividade é indissociável do pensamento: "para compreender a fala de outrem não basta entender as suas palavras - temos de compreender o seu pensamento. Mas nem mesmo isso é suficiente - também é preciso que conheçamos a sua motivação" (p.188).

Vigotski (1927/1995) e Vigotsky (1931/2007) reforçam a importância da afetividade na constituição do humano ao descrever o sujeito como biopsicossocial, constituído por corpo, afeto, cognição e meio social de modo indissociável, em que um é causa e efeito do outro, produto e produtor do outro, cuja fragmentação para se estudar o desenvolvimento humano, conforme proposto pelo autor.

Outra questão bastante enfatizada por Vigotski (1927/2004) e que mostra a relevância da afetividade em sua obra é a crítica que faz em relação à polarização das dimensões afetiva e cognitiva, praticada pela Psicologia do início do século XX. Essa crítica, além de expressa no clássico "Significado Histórico da Crise da Psicologia", texto publicado em 1925, fica muito clara na obra "Teoria de las Emociones" (Vigotski 1933/ 2004) - estudo histórico em que retoma o modo como a emoção é tratada pelos estudiosos da época. Mas o que Vigotski compreende como afetividade, emoção e sentimento?

Sawaia (2000) aponta que a afetividade para esse autor pode ser definida como uma capacidade humana de transformar seus instintos em algo socialmente mediado pelos signos sociais, a ponto de modular nossa capacidade de ação, abandonando os impulsos e elevando-os à consciência por meio da mediação da cultura. Ela destaca que, ainda que em sua obra Vigotski se refira à afetividade como sinônimo de emoção e sentimento, ele os diferencia, pois entende a emoção como afeto mais imediato e momentâneo, ligado a algo específico; enquanto o sentimento seria a emoção sem prazo, de longa duração, que não se liga a especificidades.

A autora considera que as emoções, tal como postuladas por Vigotski, podem ser entendidas como Funções Psicológicas Superiores, visto a capacidade do sujeito de regulá-las, ou seja, elas evoluem por meio da mediação da cultura. Nas palavras de Sawaia (2000) “[...] as emoções também são funções mediadas, são sentimentos humanos superiores, pois, até o próprio organismo reage a significados de forma que as sinapses cerebrais são mediadas socialmente" (p.14).

Um dos conceitos de Vigotski que integra a afetividade é o de vivência.

\section{Vivência e situação social de desenvolvimento}

Vygotsky (1925/2001), em sua obra "Psicologia da Arte", afirma que por meio da arte, a emoção nos liberta dos recalques, nos orienta, nos motiva, dá novas forças e possibilita uma melhor organização do nosso comportamento. Para o autor, as emoções possuem 
uma tendência a traduzir-se em forma de ação, e a arte faz manifestar a vontade e eleva essa predisposição à ação. Ele afirma que esses aspectos possibilitam a melhor organização do nosso comportamento uma vez que promovem a conscientização do que sentimos, possibilitando a reorganização de nossas ações. Sua importância se destaca não apenas pelo aspecto estético, mas pelos afetos que desperta por intermédio da vivência que a arte promove.

Vigotski acredita, assim, ser possível adentrar e transpor questões relativas ao humano por meio do sensível. Prestes (2010), estudiosa e tradutora da obra de Vigotski do russo para o português, afirma que: ... . Para ele a arte tem a função de superação do sentimento individual e o aspecto criativo da arte está no fato de ela possibilitar a transferência de uma vivência comum. E é esse termo vivência (em russo perejivanie) que tem enorme significado para Vigotski (Prestes, 2010, p.117).

Prestes (2010) descreve que há muitas traduções do russo para outras línguas do termo perejivanie ${ }^{3}$, como sendo experiência. Mas para ela, não seria adequado traduzir o termo russo desta forma, pois ele significa muito mais do que experiência, e a melhor tradução seria a expressão vivência. Perejivanie, como sugere Prestes, deve ser entendida como uma relação interna de uma pessoa com a realidade; o foco é a relação, a unidade entre ambos.

Quando Vigotski (1933-1934/2006b) descreve o desenvolvimento infantil em sua conferência sobre a crise dos sete anos ele explicita o termo vivência. Para o autor, nesta fase da vida, a criança já pode atribuir sentidos pessoais aos acontecimentos e já consegue fazer uma generalização de sua percepção e conferir predicados pessoais aos aspectos de sua vida. Isto ocorre porque a criança desenvolve nesta fase uma diferenciação perceptiva dos objetos, de suas impressões que já vêm com sentidos próprios, em que um ponto de vista é diferente do outro. A isto Vigotski chama de 'generalización del proceso interno' (Vigotski, 1933-1934/2006b, p.379). Já não vê um objeto isolado, com uma associação simplista, mas um processo mais desenvolvido, em que consegue fazer conexões, abrin- do espaço para uma percepção generalizada e atribuída de sentidos, incorporando vários aspectos de si, de suas vivências, de suas relações e do ambiente de forma imbricada.

No momento em que a criança produz este desdobramento de conexões e reconexões de suas vivências e confere sentidos cada vez mais complexos às suas percepções ela está experimentando outra etapa de desenvolvimento. Seu meio externo mudou, suas relações mudaram e suas experiências internas também. As ações passam a ser mediadas por várias influências que absorve do mundo de acordo com suas experiências próprias, empreendidas com o meio e sob a influência de sua personalidade, recriando uma vivência singular.

Vigotski (1933-1934/2006b) considera, assim, que a vivência possui um aspecto biossocial que revela a relação entre a personalidade da criança e o meio, e coloca o conceito de vivência como uma unidade que incorpora o interno e o externo. Sugere, então, que a vivência possa ser tomada como unidade de estudo, visto que ela seria a tradução daquilo que o sujeito pensa, sente e mantêm com o seu entorno.

Deste modo, a vivência pode nos revelar o sujeito, sua personalidade, suas motivações, afetos e como tudo isto se manifesta no meio ou sob sua influência. Portanto, para Vigotski, o estudo das vivências não pode ser reduzido à investigação das condições externas do sujeito, tampouco pode ser focalizado de forma linear porque o desenvolvimento ocorre em etapas integradas, que incorporam a anterior e a seguinte (Vigotski, 1933-1934/2006a; 1933-1934/2006b).

O que diferencia o vivido no passado do que está sendo vivido no presente é que a vivência atual passa por uma reestruturação. E a reestruturação vem justamente de demandas do meio e das interações do sujeito com ele. Quando este processo se modifica, as necessidades e motivos do sujeito também mudam e Vigotski afirma que este processo é o próprio motor que movimenta suas ações: as vivências precisam se ajustar a este novo fenômeno e toda esta dinâmica é o que pontua uma crise do sujeito.

$\boldsymbol{\nabla} \nabla \boldsymbol{\nabla} \nabla$

$\mathbf{3}$ O termo perezhivanie ou perejivanie pode ser encontrado nestas duas formas de escrita, mas aqui optou-se por escrevê-lo como os autores citados o descrevem em suas obras. 
E é sobre essa característica do meio, que pode promover mudanças no sujeito que se falará a seguir: a Situação Social de Desenvolvimento (SSD). Para haver vivência é necessária uma situação que a suscite. Vigotski (1933-1934/2006b), ao se referir ao meio, não o considera como um fator puramente ambiental, mas como movimento relacional entre o interno e o externo que configuraria uma situação sui generis, única, que ele denomina de SSD. Para Vigotski (1933-1934/2006b), como o sujeito vivencia algo se modifica na medida em que se modificar sua SSD.

González-Rey (2009b) descreve que só é possível compreender vivência por meio da SSD. Todo evento externo só se torna psicológico por meio de uma vivência que, por sua vez, é resultado de características psíquicas do sujeito como experiência singular e imprevisível. Os aspectos do ambiente não são dados, mas são construídos e se tornam importantes para o processo de desenvolvimento humano a partir do momento em que eles se transformam em uma experiência emocional (perezhivanie) para o sujeito.

A partir dessas considerações, é possível definir vivência como uma experiência significativa para o sujeito, recheada de emoções, gerada em uma situação específica (SSD), que não se configura como externa, mas como junção dos aspectos do sujeito e da própria situação. Visto que a vivência resulta na configuração de novos sentidos e significados pelo sujeito, ela pode ser tomada como unidade da consciência. Nas palavras de Vigotski (1935/2010):

A vivência é uma unidade na qual, por um lado, de modo indivisível, o meio, aquilo que se vivencia está representado - a vivência sempre se liga àquilo que está localizado fora da pessoa - e, por outro lado, está representado como eu vivencio isso, ou seja, todas as particularidades da personalidade e todas as particularidades do meio são apresentadas na vivência, tanto aquilo que é retirado do meio, todos os elementos que possuem relação com dada personalidade, como aquilo que é retirado da personalidade, todos os traços de seu caráter, traços constitutivos que possuem relação com dado acontecimento. Dessa forma, na vivência, nós sempre lidamos com a união indivisível das particularidades da personalidade e das particularidades da situação representada na vivência (p.686).

\section{Materialismo dialético como método}

Incomodado com a pouca profundidade com que as vertentes subjetivas e objetivas da psicologia explicavam os fenômenos psicológicos, Vigotski (1927/ 2004), partindo de uma análise critica, postula os fundamentos epistemológicos que davam sustentação à investigação do psiquismo com a amplitude de uma ciência completa e, segundo o autor, isto só seria possível pelo materialismo dialético. Os embasamentos do método defendido por Vigotski estão alicerçados no estudo do psiquismo a partir da análise dialética da atividade humana, nas relações estabelecidas a partir das situações de trabalho e na realidade histórica. Dessa perspectiva, Vigotski (1927/1995, 1927/2004) propõe o estudo dos fenômenos psíquicos de forma a conhecer sua essência, o que demanda investigar desde sua gênese.

Segundo Vigotski (1927/1995), o objeto e o método de investigação em Psicologia mantém uma relação muito estreita: "A elaboração do problema e do método se desenvolvem conjuntamente, ainda que não de modo paralelo" (p.47). A questão do método nas pesquisas com aporte teórico da Psicologia Histórico-cultural tem um duplo desafio: deve se constituir, a um só tempo, ferramenta e resultado da investigação, demandando, portanto, um trabalho de construção permanente do pesquisador.

Para Vigotski, "... . Estudar algo historicamente significa estudá-lo em movimento no seu desenvolvimento histórico. Essa é a exigência fundamental do método dialético" (1927/1995, p.67). O que o autor quer dizer é que ao abranger, no estudo de dado fenômeno, todas as suas fases e mudanças, desde o momento de seu aparecimento até que deixe de aparecer, o pesquisador "dá visibilidade a sua natureza" (1927/1995, p.67) e, desse modo, pode conhecer sua essência, visto que ele (o fenômeno) só se mostra quando em movimento.

Outro aspecto fundamental no método proposto por Vigotski é a perspectiva de que se parte para a análise dos processos psicológicos: deve-se partir dos mais complexos para se explicar os mais simples. Ou seja, no estudo dos problemas educativos, por exemplo, demonstrar como os problemas presentes no sistema de ensino, na escola, nas práticas docentes se objetivam 
na aprendizagem e desenvolvimento do aluno. Essa objetivação deve ser entendida como, a um só tempo, expressão e fundamento da condição de aprendizagem e desenvolvimento. Logo, a análise não pode deixar de considerar as relações entre as partes e o todo, visto que ambos são determinados e se determinam, mutuamente.

Para Vigotski (1927/1995), a tarefa fundamental da análise é "[...] destacar do conjunto psicológico integral, determinados traços e momentos que conservam a primazia do todo" (p.99). O que possibilita a realização desse tipo de análise é conhecer o sujeito em movimento, nas relações que estabelece em seu contexto, investigando as condicionantes dessas relações, visto serem elas que promovem a emergência do sujeito tal como se manifesta. Deste modo, sujeito e realidade se imbricam em um processo de constituição mútua. Assim, o método deve focalizar as relações, pois é nelas que o movimento entre o singular e o coletivo se expressa.

\section{Contribuições da psicologia histórico-cultural às práticas psicológicas em instituições}

Dellari Jr. (2009) ressalta que ainda que a teoria de Vigotski no Brasil esteja comumente relacionada aos temas da educação e do desenvolvimento humano, ela tem lastro para subsidiar a atuação do psicólogo em diferentes contextos práticos. Defende o autor, que os fundamentos da Psicologia Histórico-Cultural possibilitam compreender o ser humano de modo sistêmico, que articula suas dimensões históricas, interrelacionais e pessoais e, quando o profissional de psicologia se utiliza desses princípios, ele empreende, também, uma ação favorecedora do desenvolvimento e transformação humanos.

Entende-se que reunir alguns dos principais conceitos de Vigotski abre novas perspectivas de reflexão e atuação para o psicólogo. Em nosso grupo de pesquisa temos nos mobilizado para produzir compreensões de como aplicar esses princípios nos tipos de pesquisa que realizamos e de que modo operacionalizá-los em procedimentos que permitam acessar e intervir nos fenômenos psicológicos pesquisados. Desta perspectiva, propõem-se que esses conceitos vigotskianos possam subsidiar as práticas profissionais do psicólogo em instituições, com posturas e ações que arrolou-se a seguir:

- Investir no diálogo como espaço de manifestação dos sujeitos, em que o exercício da fala e da escuta possa promover a reconfiguração de sentidos e significados das experiências vividas no contexto institucional;

- Desenvolver ações envolvendo o coletivo, em que se busque identificar os afetos e motivos que estão na base das ações dos sujeitos, refletindo, com o grupo, sobre as implicações de seu modo de pensar e agir para si e para o outro;

- Abrir espaços à reflexão, oferecendo elementos que garantam a expressão de cada um, valorizando a diversidade de concepções, de modos de ser e agir;

- Oferecer conhecimentos que possibilitem aos sujeitos ampliarem suas percepções sobre suas condições de trabalho, identificando as condicionantes do modo de produção característico de seu âmbito de atuação;

- Utilizar a arte como materialidade que favorece a expressão de afetos, pela apreciação de linguagens artísticas como, música, poesia, artes visuais e filmes, favorecendo, assim, a elaboração de emoções e sentimentos pela reflexão sobre os aspectos da obra;

- Estimular os sujeitos à superação dos limites por meio da cooperação, propondo alternativas de ações que possam transformar uma situação social conflituosa na direção de encontros mais saudáveis.

Propõem-se, assim, que o psicólogo, valendo-se dos conceitos da Psicologia Histórico-Cultural, possa atuar como facilitador do processo do sujeito em se ver como integrante e produtor de sua condição social e, assim, identificar a dinâmica dos diferentes espaços grupais e institucionais nos quais ele se constitui. Entende-se essa ação profissional como processo de mediação, que favorece a construção das situações sociais de desenvolvimento, promotoras de vivências que produzam a compreensão dos múltiplos significados e dos processos de ressignificação. Abrem-se, deste modo, possibilidades de atuações que potencializam o desenvolvimento das funções psicológicas superiores, por meio da reorganização das ações e da consciência sobre si e sobre a realidade. 


\section{Considerações Finais}

Apresenta-se, neste artigo, apenas uma parte de nossas leituras sobre a obra de Vigotski, porém, com a preocupação de focalizar conceitos básicos para o entendimento do que este autor pretendia apontar como novos rumos de uma Psicologia que ele chamava de completa, visto que buscava entender o humano em toda sua complexidade, de uma maneira holográfica e sistêmica, como chega a afirmar em sua obra 'O significado histórico da crise da psicologia' (Vigotski 1927/2004a). O autor, devido à complexidade de sua obra, demanda investidas incansáveis em seu estudo, o que continuamos a fazer, mesmo porque muitos de seus escritos ainda são desconhecidos, não estão publicados. Têm-se notícia de que estaria em curso a organização de suas obras completas, visto que até o momento o material mais vasto de que dispõe-se são suas obras escolhidas, com seis tomos publicados, em espanhol e em inglês. Logo, ainda há muito que se investir para a compreensão do lastro que podem ter os conceitos da Psicologia Histórico-Cultural.

O artigo, finaliza como intento em oferecer subsídios à reflexão sobre as proposições do autor, destacando, ainda, alguns elementos fundantes de sua obra.

Ao postular o "sujeito histórico" como objeto de investigação da psicologia, Vigotski expressa uma visão de sujeito que incorpora, de modo inseparável, o social como "fonte" de desenvolvimento e não como aspecto que o influencia. O sujeito histórico abrangeria, da perspectiva da totalidade, a consciência, as funções psicológicas superiores e a personalidade. Tal acepção o conduz a propor a vivência como unidade de análise, o que nos parece justificável uma vez que essa proposição possibilita atender ao princípio de estudar e intervir no processo com foco no objeto em transformação, sobretudo nas conexões entre os movimentos, o que equivale a explicar de que modo e por que uma realidade social se transforma e engendra outras. A vivência seria uma experiência que une a personalidade do sujeito e o meio, este último entendido como situação social de desenvolvimento, visto ser produzido socialmente, incluir os aspectos da cultura, sendo, portanto, "fonte" do desenvolvimento do psiquismo.
Assim, trabalhar com o conceito de vivência implica tratar da unidade sujeito-social, constituída por uma situação social de desenvolvimento específica. É, pois, por intermédio da vivência, promovida e vivida na situação social de desenvolvimento, que o sujeito pode aceder a novos modos de funcionar, pela transformação de dadas funções psicológicas superiores que, por sua vez, promovem a transformação de todo o sistema psicológico. Uma realidade social se transforma e se engendra a outras, possibilitando ações que promovem a conscientização do sujeito por meio da reelaboração de sentidos e significados, transformando-se a si e ao contexto ao seu redor.

\section{Referências}

Barros, J. P. P., Paula, L. R. C., Jesus, G. P., Colaço, V. F. R., \& Ximenes, V. M. (2009). O conceito de "sentido" em Vygotsky: considerações epistemológicas e suas implicações para a investigação psicológica. Psicologia \& Sociedade, 21(2), 174-181.

Delari Jr., A. (2009). Vigotski e a prática do psicólogo: em percurso da psicologia geral à aplicada. Umuarama: GETHC. Recuperado em setembro 14, 2012, disponível em <http:// vigotski.dominiotemporario.com/vigprat.pdf>.

González-Rey, F. L. (2009a). La significación de Vygotski para la consideración de lo afectivo en la educación: las bases para la cuestión de la subjetividad. Actualidades Investigativas en Educación, 9(Esp.), 1-24.

González-Rey, F. L. (2009b). Historical relevance of Vygotsky's work: Its significance for a new approach to the problem of subjectivity in psychology. Outlines Critical Practice Studies, 11(1), 59-73.

Leontiev, A. N. (1978). O desenvolvimento do psiquismo. Lisboa: Livros Horizonte.

Palangana, I. C. (1998). Desenvolvimento e aprendizagem em Piaget e Vygotsky. São Paulo: Plexus.

Prestes, Z. R. (2010). Quando não é quase a mesma coisa: análise de traduções de Lev Semionovitch Vigotski no Brasil: repercussões no campo educacional (Tese de doutorado não-publicada). Programa de Pós-Graduação em Educação, Universidade de Brasília.

Puzirei, A. (1989). Notes to: Vigotski, L. S. (1929/1989) concrete human psycology. Soviet Psycology, 17(2), 39-53.

Sawaia, B. B. (2000). A emoção como locus de produção do conhecimento: uma reflexão inspirada em Vygotsky e seu diálogo com Espinosa. Anais da III Conferência de Pesquisa Sócio-cultural (pp.1-25). Campinas. Recuperado em julho 10, 2011, disponível em <www.fae.unicamp.br/ br2000/trabs/1060.doc>.

Toassa, G. (2009). Emoções e vivências em Vigotski: investigação para uma perspectiva histórico-cultural (Tese de doutorado não-publicada). Programa de Pós-Graduação em Psicologia, Universidade de São Paulo. 
Tunes, E., \& Prestes, Z. (2009). Vigotski e Leontiev: ressonâncias de um passado. Cadernos de Pesquisa, 39(136), 285-314. Recuperado em março 20, 2010, disponível em <http:// www.scielo.br>.

Vigotski, L. S. (1995). Obras Escogidas III: problemas del desarrollo de la psique. Madrid: Visor. (Originalmente publicado em 1927).

Vigotski, L. S. (2004a). O problema da consciência. In L. S. Vigotski. Teoria e método em psicologia (3a ed., pp.171-189). São Paulo: Martins Fontes. (Originalmente publicado em 1925).

Vigotski, L. S. (2004b). Sobre os sistemas psicológicos. In L. S. Vigotski. Teoria e método em psicologia (3a ed., pp.103-135). São Paulo: Martins Fontes. (Originalmente publicado em 1925).

Vigotski, L. S. (2004). O significado histórico da crise da psicologia: uma investigação metodológica. In L. S. Vigotski. Teoria e método em psicologia (3a ed., pp.203-417). São Paulo: Martins Fontes. (Originalmente publicado em 1927).

Vigotski, L. S. (2004). Teoría de las emociones. Madrid: Ediciones Acal. (Originalmente publicado en 1933).

Vigotski, L. S. (2006a). Desarrollo de las funciones psíquicas superiores en la edad de transición. In L. S. Vigotski. Obras escogidas IV: psicología infantil (2a ed., pp.117-203). Madrid:
Visor y A. Machado Libros. (Originalmente publicado en 1933-1934).

Vigotski, L. S. (2006b). La crisis de los siete años. In L. S. Vigotski. Obras escogidas IV: psicología infantil (2a ed., pp.377-386). Madrid:Visor y A. Machado Libros. (Originalmente publicado en 1933-1934).

Vigotski, L. S. (2010). Quarta aula: a questão do meio na pedologia. Psicologia USP, 21(4), 681-701. Recuperado em setembro 10, 2012, disponível em <http://www.scielo. br>. (Originalmente publicado em 1935).

Vigotsky, L. S. (2007). A formação social da mente: o desenvolvimento dos processos psicológicos superiores (7a ed.). São Paulo: Martins Fontes. (Originalmente publicado em 1931).

Vygotski, L. S. (2001). Pensamiento y lenguage. In L. S. Vygotski. Obras escogidas II: problemas de psicología general (2a ed., pp.9-348). Madrid: Visor. (Originalmente publicado en 1934).

Vygotsky, L. S. (2001). Psicologia da arte (2a ed.). São Paulo: Martins Fontes. (Originalmente publicado em 1925).

Vygotsky, L. S. (2003). Pensamento e linguagem (3a ed.). São Paulo: Martins Fontes. (Originalmente publicado em 1934).

Recebido em: 16/5/2012

Versão final em: 5/10/2012

Aprovado em: 7/12/2012 